\title{
Responsibilities and role of the consultant psychiatrist in the multidisciplinary team
}

A small working group has recently been established, under the chairmanship of the President, to produce a policy statement setting out the core responsibilities of consultant psychiatrists and their role in the NHS, and elaborating on the role of consultants in each of the psychiatric specialties. It is intended that this statement will clarify the statutory and other responsibilities of the consultant psychiatrist in all areas of psychiatric practice.

Membership of this group includes the Registrar, the Dean, and representatives from the Specialist Sections of the College, the Liaison Psychiatry Group, the Collegiate Trainees Committee, and the College Research Unit.

Members wishing to contribute to this debate are invited to forward their comments to the
College Secretary as soon as possible, as it is proposed that the statement will be submitted to the forthcoming meeting of Council on 25 January 1994.

At a later stage, it is proposed that the working group will address further related issues, including the relationship between the consultant psychiatrist and non-medical members of the multi-disciplinary team, medical responsibility for patients referred directly to non-medical members of the team, and appropriate levels of cover for in-patient psychiatric services, and the distance from an acute or non-acute unit that medical staff should be resident.

Vanessa Cameron, The Secretary. The Royal College of Psychiatrists
Noman Nadhim Bayatti, formerly Consultant Child and Adolescent Psychtatrist, Wigan Health Authortty

Noman Bayatti died on 6 February 1993 having borne more than two years of illness with courage and dignity.

Noman was born in Iraq and qualified MB ChB Baghdad in 1965; he eventually settled in England in 1978. Previously he had spent time here both as a schoolboy and as a junior doctor in paediatrics, obtaining the DCH (RCPGlas) in 1970. He returned to England to pursue a career in child psychiatry, becoming senior registrar in Exeter before taking up his consultant appointment in 1987. He was elected MRCPsych in 1984.

His patients benefited from his undoubted clinical skills, and his colleagues from his wisdom and humanity. Noman was an engaging and literary conversationalist with a gentle sense of humour.

All who knew him were saddened by his untimely death, and our particularly sympathy goes to his wife Amal and their three children. Family, friends and colleagues attended a Memorial Service in Noman's honour on 8 May 1993.

\section{P. A. CoOK}

Charles Mathurin Vaillant, formerly Consultant Psychiatrist, Walton Hospital, Luerpool

Charles Mathurin Vaillant, the son of a Liverpool general practitioner, died on 24 August 1993. He was born on 27 November 1906, and was educated at Stoneyhurst College following which he went up to Trinity College Oxford, where he read Physiology, graduating BA(Hons) in 1927. He continued his medical studies at Liverpool University and qualified MRCS, LRCP, in 1932, and BM (Oxford) in 1934. He obtained his MRCP in 1937, and was elected FRCP in 1968. In 1949 he obtained the DPM (Conjoint) and in 1971 was elected to the foundation fellowship of the College.

Before 1939, he worked inter alla at the Royal Southern Hospital, Liverpool, under Dr William Johnson, an honorary physician with special interests in neurology and psychoneurosis.

As a TA officer in the Lancashire Yeomanry he was immediately called up for active service in 1939. He served throughout the 1939-45 War first in France prior to Dunkirk, and later in the Sudan, Egypt and India. With the rank of Lieutenant Colonel he commanded a general hospital in Northern India. He was later awarded 